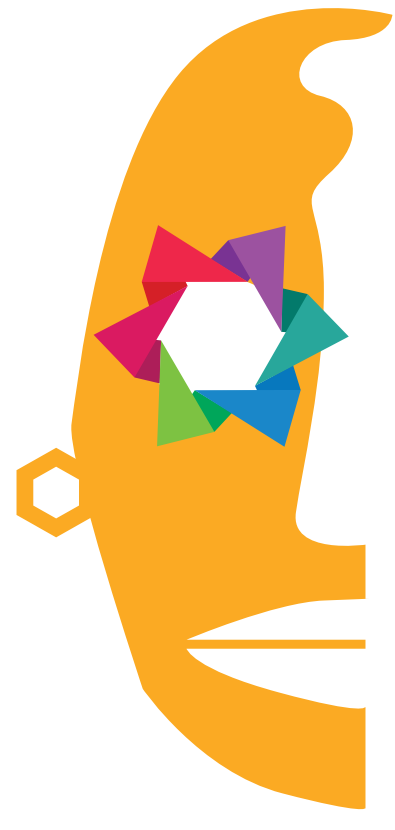

Grínor Rojo

Universidad de Chile

Chile

\title{
Humanidades, cultura y universidad en la escena histórica global
}

\section{Humanities, culture and university in the global historical scene}

\section{Resumen}

Este ensayo intenta definir qué son las humanidades y cuál es su estatuto en el doble ámbito de la cultura y la universidad contemporáneas. Trata así de determinar la relación que las humanidades tienen con la población en general y con la universidad en particular, sobre todo en los países periféricos, como los latinoamericanos, lo mismo que las consecuencias y respuestas posibles a su actual pérdida de prestigio y dignidad.

Palabras clave: humanidades, cultura, universidad, globalización

\section{Abstract}

This essay tries to define what the humanities are, and their place in the double sphere of the contemporary culture and university. Thus it attempts to determine the relationship the humanities have with the general population on the one hand, and on the other with the university, particularly in the peripheral countries, such as the Latin American, as well as the consequences and possible answers to its present loss of prestige and dignity.

Keywords: humanities, culture, university, globalization 
Este ensayo intenta definir qué son las humanidades y cuál es su estatuto en el doble ámbito de la cultura y la universidad contemporáneas. Trata así de determinar la relación que las humanidades tienen con la población en general y con la universidad en particular, sobre todo en los países periféricos, como los latinoamericanos, lo mismo que las consecuencias y respuestas posibles a su actual pérdida de prestigio y dignidad.

\section{2}

Las humanidades deben entenderse, a mi juicio, como:

a) La cultura que se encuentra ya enraizada en la población, más profundamente en algunos lugares que en otros, y de preferencia en aquellos donde resulta pertinente la propuesta de "universalidad" para los "derechos del hombre y del ciudadano", los que estableció por primera vez la Revolución Francesa. Como es sabido, esos derechos han sido ampliados y perfeccionados con posterioridad, en diversas oportunidades y por instituciones igualmente diversas, como las Naciones Unidas y sus varias agencias, y esa ampliación y ese perfeccionamiento se manifiestan en la coyuntura presente a través de la inclusión en la esfera de "lo humano" de su entorno natural o, más bien, en una reformulación de la idea de lo humano que realza su íntima sociedad con la naturaleza. Ello propicia un encuentro necesario, debido al apocalipsis climático y medioambiental ad portas, de la tradición de la cultura iluminista con otras en las que la sociedad a que me refiero existe como un hecho indiscutido. Los pueblos originarios de América Latina, sin ir más lejos. Tampoco me parece razonable que hoy sigamos pensando "lo humano" al margen de la diversidad genérico-sexual, desde un imaginario que explícita o implícitamente es masculino, algo que la rebelión feminista ha puesto de manifiesto con meridiana lucidez.

b) El quehacer de las "disciplinas humanas", las que algunos prefieren denominar "ciencias humanas", una denominación que es de fines del siglo XIX y que a mí no me gusta. Wilhelm Dilthey, en su Introducción a las ciencias del espiritu (1949), nos entrega la que ha de ser la definición más influyente en este sentido, diciendo que ciencias humanas son las que se ocupan de "los hechos espirituales que se han desarrollado en el hombre históricamente"1. Se refiere a los hechos de la historia y la sociedad [en alemán, las Geisteswissenschaften], y que constituyen una realidad "que nosotros tratamos no de

1 Wilhelm Dilthey, Obras de Wilhelm Dilthey. Introducción a las ciencias del espiritu. En la que se trata de fundamentar el estudio de la sociedad y de la historia (México y Buenos Aires: Fondo de Cultura Económica, 1949),13. 
dominar, sino de comprender". Pero en mi opinión a este alegato de Dilthey, que se asienta sobre la problemática oposición entre materia y espíritu y que reclama desde ahí el visado de cientificidad para unas disciplinas cuyo espectro tendría que extenderse a la filosofía (que originalmente incluyó a las demás, por eso algunas facultades que son como la nuestra la mantienen encabezando su nombre), a los estudios literarios, a los estudios lingüísticos, a los jurídicos, entre otros, debemos corregirlo. Dicho de una manera más precisa: yo creo que las disciplinas humanas (y no las ciencias del espíritu o las ciencias humanas) son aquellas que convierten en objeto teórico, y luego en materia de investigación y de estudio, la percepción de lo humano que en un momento y un lugar determinados, en nuestro caso en el tiempo y espacio de la modernidad tardía, con la reformulación que ya indiqué y a la que el poeta Elicura Chihuailaf ha descrito mejor de lo que yo puedo hacerlo ${ }^{2}$, constituye la cultura de Occidente.

Así entendidas, las humanidades se ponen en contradicción abierta con lo que los filósofos de la Escuela de Frankfurt llamaron el "discurso instrumental" de la razón moderna, alineándose con su opuesto, el "discurso emancipador". Más ceñidamente: yo postulo aquí que el discurso instrumental de nuestro tiempo, sin que haya que endosárselo en exclusiva al discurso de la economía capitalista y sus secuelas, sociales, políticas e ideológicas, es por antonomasia suyo y que no resulta compatible con el discurso de las humanidades en última instancia. El argumento respectivo lo expuse en mi "Capitalismo, humanidades y pandemia" y dice así: "el foco del celo del capitalismo no está puesto en el valor de uso, que es el resultado del proceso de trabajo, sino en el valor de cambio, que es el resultado de la valoración del capital. La consecuencia que esto tiene es que al capitalista el ser humano le concierne menos por lo que es que como un medio para generar unos bienes y servicios cuyo valor se determinará no de acuerdo con el esfuerzo que se haya empleado para producirlos/ejecutarlos o de la falta que puedan hacerle a la comunidad, sino por la demanda de parte de quienes poseen el dinero para comprarlos [...] Las humanidades, en tanto que modeladoras de nuestra conducta y objeto de un haz de disciplinas especializadas del conocimiento, existen porque desde atrás las alimenta una cierta idea (no una esencia metafísica, por lo tanto)

2 "La lucha por la defensa de nuestra tierra tiene que ver con la Ternura, dice nuestra gente. Porque ella --para todos los Pueblos indígenas del continente y del mundo-- es la Madre Tierra. Es Ella quien nos cobija y nos regala su agua, su luz, su aire, sus alimentos. Somos sus hijos e hijas, somos sus Brotes, que poco a poco, de generación en generación, vamos escuchando sus misterios que nos enseñan a mejorar nuestra manera de pensar, nuestra manera de vivir en su conocimiento de la reciprocidad [...] la propiedad comunitaria tribal del suelo constituye, en los pueblos antiguos del mundo, una regla general; en tanto que la privada es una excepción que tiende a generalizarse en el desarrollo de las concepciones de la sociedad absolutista imperial y de la sociedad burguesa. La humanidad ha vivido épocas muy milenarias bajo ese régimen de propiedad comunitaria, y épocas muy breves, inestables, revoltosas y bélicas, bajo el de la propiedad privada”. Elicura Chihuailaf Nahuelpan, Recado confidencial a los chilenos (Santiago de Chile: LOM, 1999), 128 y 139. 
acerca de la magnitud y la dignidad de lo humano. Esta idea fundante de sus intervenciones en el mundo sostiene que las personas son personas y no recursos y que por eso ellas valen no solo por el rendimiento mercantil que puede extraérseles, es decir no por su funcionalidad como productores y compradores de mercancías, sino por (en) la entera dimensión del horizonte dentro del que son capaces de actualizar su potencial"’.

Correlativamente, si pensamos en lo humano e incluimos dentro de eso humano a su entorno, de ello se sigue que en la explotación de la naturaleza tampoco debiera primar el valor de cambio, su valor de "recurso", habiéndose redefinido a la naturaleza como un "capital". La primacía tiene que concedérsele a su valor de uso, al cómo la naturaleza forma un todo con la humanidad contribuyendo cada una con lo suyo en un ciclo de cuidado y preservación recíprocos.

En el tiempo contemporáneo, al que yo caracterizo como uno de crisis del capitalismo tardío y de una tentativa de reacumulación echando mano de no importa cuáles sean los métodos, las tendencias antihumanas del sistema se reafirman y refuerzan, en la medida en que este, para salir del atolladero en que se encuentra inmerso, redobla el uso de sus peores mecanismos. Se intensifica por lo tanto corrientemente la contradicción que ha existido desde los comienzos de la modernidad entre el capitalismo y las disciplinas humanas. Si al mismo tiempo, en la explotación de la naturaleza, se sacrifica a la reacumulación capitalista el vínculo de protección recíproca que la naturaleza tiene con la humanidad, el panorama se oscurece aún más y son las disciplinas concernientes las que se encargan de acusar el error y medir sus consecuencias.

Consistentemente, el sistema económico capitalista y sus secuelas (la sociedad, la política y la ideología burguesas) han mostrado respecto de las disciplinas humanas una triple actitud. La primera es un remanente residual, por cuanto se limita a mantener la unión premoderna de estas disciplinas con la superstición y el prejuicio. La segunda, ya moderna, las considera no mucho más que un ornamento, cuya presencia en la formación y estilo de vida del ciudadano "se ve bien", garantizándole a este una cuota de prestigio social. La tercera, esta vez con algo más de finura, las incorpora en el desarrollo continuo y el mapa consecuente de la división del trabajo intelectual. En este tercer escenario, las humanidades ocupan un área entre las varias que constituyen el conocimiento moderno. Esto se puso de relieve concretamente con el surgimiento de las distintas "facultades" de la universidad moderna (en el mundo angloamericano, los "colleges").

3 [En prensa] Grimor Rojo, "Capitalismo, humanidades y pandemia”, en Proposiciones. Ensayos de teoría crítica (Santiago de Chile: Universitaria, 2021), 16 y 17. 
Fue el tema de Immanuel Kant, quien se dio cuenta de que en la universidad moderna entraban en "conflicto" una fuerza "heterónoma", proveniente de un fundamento extrauniversitario, la de las facultades "superiores", teología, derecho y medicina, con una fuerza "autónoma" y de fundamento universitario, la de la Facultad "inferior", la de Filosofía. Escribió entonces: "se mire como se mire, todavía hay que conceder a la comunidad científica otra Facultad, que sea independiente de los mandatos del gobierno con respecto a sus doctrinas y tenga la libertad, no de dar orden alguna, pero sí de juzgar todo cuanto tenga que ver con los intereses científicos, es decir, con la verdad, terreno en el que la razón debe tener el derecho de expresarse públicamente, ya que sin ello la verdad nunca llegaría a manifestarse (en perjuicio del propio gobierno), dado que la razón es libre conforme a su naturaleza y no admite la imposición de tomar algo por verdadero (no admitiendo crede alguno, sino tan solo un credo libre)"4.

La convivencia entre facultades le pareció a Kant factible, sin embargo, y nosotros podemos suponer que hasta provechosa, aun cuando un espacio de prominencia y sobre todo autónomo para la Facultad de Filosofía -depositaria esta de la verdad de la razón vis-à-vis el interés extrauniversitario e independientemente del origen y la forma de este-, debía a su juicio constituir una prioridad, afirmación esa que al filósofo le costó un tirón de orejas de parte del rey. Pero no solo eso, ya que la subdivisión continuó progresando a un ritmo imparable. Por ejemplo, los estudios literarios adquirieron el estatuto de una disciplina académica diferenciada a mediados del siglo XIX, cuando Abel-François Villemain los empezó a impartir en La Sorbona. Pero, con cualquiera de las dos actitudes propiamente modernas, el sistema limaba el filo rebelde del saber humanístico.

Al poner a un lado el remanente residual, hoy, en el campo epistemológico de una modernidad que no disfruta de la mejor salud, siguen estando en pie las dos estrategias modernas, solo que reconfiguradas y exacerbadas. La primera actúa de preferencia por medio de las industrias de la cultura en su versión 2021, promotoras estas de la banalización cultural en una cuantía y con una voluntad de penetración que no se habían visto anteriormente en la historia de la especie.

Por cierto, el medio universitario no es inmune a la voluntad de penetración de las industrias culturales. Esto sin importar cuál sea el vehículo al que se recurra para contagiarlo: la palabra (oral o escrita) o la imagen (sobre todo la de la "pantalla", en el apogeo de lo que el comunicador catalán Román Gubern llamó hace algunos

4 Immanuel Kant. El conflicto de las facultades (Madrid: Alianza, 2003), 65-6. Añado que no muy diferente fue la posición de Andrés Bello en su "Discurso de instalación de la Universidad de Chile", donde hace confiesa su preferencia por la facultad que se ocupa del cultivo de la "inteligencia contemplativa", la que "descorre el velo de los arcanos del universo físico y moral" y que, a su juicio, es "en sí mismo un resultado positivo y de la mayor importancia". 
años "el desbocado proceso de pantallización de la sociedad moderna, seguida por las activas pantallas emisoras de la televisión, de las computadoras, de los video juegos, del teléfono celular, del GPS, del radar, de los cajeros automáticos y de los centros de videovigilancia"s).

Pero, cualesquiera sean sus aterrizajes concretos, no deja de ser digno de nuestra advertencia que el soporte "imagen" haya ganado en los últimos 50 años terreno respecto del soporte "palabra" (o "letra" o "libro"). En esta misma línea de pensamiento, recordemos aquí que en su Dialéctica de la Ilustración (2009) Adorno y Horkheimer reaccionaron contra las perversiones de la televisión temprana, la que ellos conocieron en la mitad del siglo XX, apuntando a sus "posibilidades ilimitadas", que según lo veían estaban en proporción directa con el empobrecimiento de lo "estético", pero aun así, no obstante su profética lucidez, no llegaron a dimensionar el aspecto monstruoso que adquiriría 50 años después el adjetivo "ilimitadas". La banalización de la cultura de Occidente avanza hoy con la velocidad de la luz, de la mano con la revolución digital, lo que no quiere decir, entiéndaseme bien, que la revolución digital sea la causa de la banalización (una opinión bastante común, en la huella de los heideggerianos de "La pregunta por la técnica" y de los benjaminianos de "La obra de arte en la época de la reproductividad técnica") o que en otras condiciones no puedan separarse la una de la otra (una opinión también común). Hay que aclararlo: una cosa es el progreso tecnológico, que es un progreso de las herramientas, y otra distinta es lo que hacen con él los carpinteros.

La segunda estrategia moderna consiste en el arrinconamiento de las disciplinas humanísticas al interior de un cubículo aparte dentro del espacio que ocupan las disciplinas del conocimiento, y su consideración es determinante para descubrir y describir lo que acontece con ellas en el recinto universitario. Sí, es cierto, los universitarios nos quejamos todos los días de que entre las distintas facultades que dan su forma a la institución que nos alberga la de humanidades es el pariente pobre, que en el reparto del presupuesto institucional perdemos como en la guerra y que en el imaginario de nuestros compatriotas nuestro prestigio (si es que alguno nos queda) anda por los suelos, ya que lo que decimos los humanistas se prejuzga cosa flácida y que a nadie le debiera importar. Eso es efectivo, pero no demasiado importante. Más importante es comprobar que nada de ello es consecuencia de las políticas de esta o de aquella autoridad universitaria. Cuando mucho, podría acusarse a la autoridad de una obsecuencia mansa, de haber sido un engranaje disciplinado a las exigencias de la máquina, entregando nuestra casa dócilmente a

5 Román Gubern, Metamorfosis de la lectura (Barcelona: Anagrama, 2003), 94.

6 Max Horkheimer, Theodor Adorno, Dialéctica de la Ilustración. Fragmentos filosóficos (Madrid: Trotta, 2009), 165 y ss. 
las presiones del todo económico y social dentro del cual las diversas prácticas se articulan hogaño en el mundo. Como en los demás que lo constituyen, los grandes cambios que ocurren en el segmento que a nosotros nos toca dentro de ese gran reparto no se producen en virtud del esfuerzo individual sino que son estructurales. Es el todo económico y social el que le impone a la institución universitaria un objetivo y unos comportamientos y es hacia su núcleo de significación y de acción hacia donde nosotros debemos dirigir ahora la mirada.

Previsiblemente, el objetivo que se nos está imponiendo hoy a los universitarios consiste en entregar nuestro aporte a la tarea de reenergizar el sistema capitalista mundial, mismo que se encuentra (y que se sabe, para lo que se escuchan explicaciones que se bandean entre la hipocresía y la idiotez) en un estado de crisis profunda. No es que el sometimiento del quehacer universitario a los fines del capitalismo sea un fenómeno nuevo, sin embargo. Como dije más arriba, ha estado presente en la historia entera de la modernidad, por lo menos desde el estreno de la universidad napoleónica, pero se acelera y se profundiza en el siglo XX, después del término de la Segunda Guerra Mundial, en un periodo de crecimiento explosivo de la economía de los Estados Unidos, cuando ese crecimiento les permitió a los habitantes de aquel país, según el dictamen de Eric Hobsbawn, disfrutar de una "edad de oro"

Pero esa fue una etapa menos larga de lo que sus parroquianos esperaban y que se cortó (o que empezó a cortarse) a comienzos de la década del '70, abriéndose entonces una etapa de crisis que desde entonces hasta ahora no ha hecho más que ahondarse. Fue Richard Nixon quien en 1971 puso fin en Estados Unidos al patrón oro para el dólar, a lo que se añadió en 1973 y 1974 un aumento de los precios del petróleo. Entre 1982 y 1989 se desató la llamada "crisis de la deuda", que impactó a los países latinoamericanos principal, pero no exclusivamente; en 1997, en el sudeste asiático se produjo un dominó de devaluaciones devastadoras; diez años después, en 2007, sobrevino el caos financiero, cuando Lehman Brothers fue el primero dentro de una familia de bancos estadounidenses que se declararon en quiebra; el de 2008, cuando estalló la burbuja inmobiliaria española; el de 2012-2013, cuando en la eurozona quedaron 24.7 millones de personas sin trabajo; el de 2015-2016, cuando cayeron en picada los precios de la materias primas, como los chilenos pudimos experimentarlo con el cobre y los venezolanos, mexicanos y ecuatorianos con el petróleo. Hoy el COVID-19 está generando un declive económico que los más optimistas calculan significará una caída del 6\% del PIB mundial y de un $4.6 \%$ del PIB latinoamericano. Entre tanto, la "primera

7 Eric Hobsbawm, Historia del siglo XX 1914-1991 (Barcelona: Crítica, 2009), 229 y ss. 
potencia del mundo" es también el "primer deudor del mundo" (su deuda pública es superior a su PIB, del 102.3\%) y su experimento de un "Medio Oriente democrático" (capitalista, claro) acaba de irse por el caño.

El sistema mundial entró, como digo, en los años '70, en la fase descendente de su curva, debido a la atrofia de las virtualidades que en la posguerra le habían permitido crecer sin cambiar. Tenía pues que reinventarse, y la reinvención consistió no en un reemplazo del paradigma capitalista por otro, sino en un aprovechamiento a fondo de sus potencialidades intrínsecas, o sea que consistió en poner en marcha una estrategia de reacumulación pero multiplicando exponencialmente lo mismo que había hecho desde siempre. Esa fue la política de Reagan y Thatcher en los '80, misma que les desmalezó el camino a las corporaciones transnacionales y, en el paso siguiente, ya en pleno desmadre, a la globalización. $\mathrm{O}$, dicho en una sola frase, a eso que yo caractericé como el intento actual de reenergización del sistema.

El modo favorito de la reenergización capitalista contemporánea es la "globalización". El favorito, no el único. Otros modos coincidentes son el ataque al medioambiente y su depredación (lo que está haciendo Bolsonaro con la selva amazónica es el ejemplo por indecencia), la degradación del trabajo en "trabajo informal", la "automatización" del trabajo, con la consiguiente desaparición de los empleos de las personas de carne y hueso, la (infame) "flexibilización laboral", la creación en el público de "necesidades" innecesarias y necias, el gasto en las guerras expansivas y, por lo tanto, no en busca de "más democracia" sino de un nuevo contingente de proveedores y consumidores y para favorecer de paso la producción de armamentos, y suma y sigue.

En cuanto a la globalización, ella no es otra cosa que la división contemporánea de los recursos materiales y del trabajo humano, de todos los recursos materiales $y$ de todo el trabajo humano, solo que, en esta ocasión a escala planetaria, algo que Marx y Engels predijeron hace casi 200 años en las páginas del Manifiesto comunista (1848) y que Slavoj Zizek se ha preguntado si no está hoy “más vigente que nunca". Y precisa el esloveno: "la imposición brutal del mercado mundial unificado, que amenaza todas las tradiciones étnicas y locales, entre ellas la mismísima forma del Estado".

Esto se hace a partir del regreso a una perspectiva geoeconómica ricardiana, que distribuye las capacidades instaladas en cada país de los que hoy componen el mapa del mundo con la finalidad de producir bienes transables ventajosamente en el mercado. Las megaempresas que conforman la trama global y que son las que deben hacerse cargo de este proceso, según el discurso del ideologismo neoliberal y privatizador, que es su secuaz (sus instructores y voceros: el Fondo Monetario

8 Slavoj Zizek. La vigencia de El manifiesto comunista (Barcelona: Anagrama, 2018), 20. 
Internacional, el Banco Mundial, el Banco Central Europeo, el Banco Interamericano de Desarrollo, la OCDE, el G7, el G8, el G20, más una telaraña de think tanks y no sé cuántos organismos más del mismo tipo), se conectan entre sí y distribuyen las faenas. En los países subalternos, esas empresas estarán abocadas a la extracción y exportación de materias primas, las sin elaboración, en tanto las que operan en (o desde) los países centrales se dedicarán o bien a la producción y exportación de las materias elaboradas, las que requieren de una alta tecnología, o bien a la manipulación de los instrumentos financieros. Los tratados de libre comercio entre países o entre grupos de países puntualizan y legalizan los reglamentos correspondientes. Cláusulas que crean tribunales internacionales que están por encima de los tribunales nacionales y a los que se acude para defender los "derechos" de las megaempresas, preferencia otorgada por los estados a las empresas privadas y extranjeras por sobre las públicas y propias, compensaciones en situaciones de "pérdida" de ganancias, "derechos" de propiedad, entre otros. El caso del TPP-11, aprobado ya en varios países y todavía en discusión en Chile, me parece ejemplar.

Una consecuencia de esto es que en los países subalternos el deseo de sus habitantes de ser protagonistas de un conocimiento complejo deviene una fantasía falta de toda sustancia, algo así como el anhelo de un derroche irresponsable, lo que, como es lógico, repercute en el quehacer universitario. Los montos asignados a investigación en los países con grados de desarrollo asimétrico lo demuestran: Chile, donde un solo producto proporciona más del 50\% de nuestras exportaciones y entre el $10 \%$ y el $15 \%$ del PIB, destina apenas el $0.36 \%$ de ese PIB a las actividades de investigación, Alemania el 2.94\%, Japón el 3.14\%, Suecia el 3.25\% e Israel el $4.25 \%$. No he logrado averiguar a cuánto asciende el presupuesto para el cultivo de las Humanidades en Chile, pero si el dinero total que nuestro país destina a la investigación en general es de un $0.36 \%$ del PIB, ¿será una exageración mía pensar que las Humanidades no se llevan, que no pueden llevarse en ningún caso, mucho más del $0.10 \%$ ? Al dividir los recursos y el trabajo de esta manera el sistema capitalista contemporáneo se las arregla para introducir un disfraz de racionalidad que oculta la que no es sino su irracionalidad de cuna.

\section{4}

Y así es como al quehacer universitario se lo obliga a sumarse también al proyecto de remodelación del edificio global. Al potenciar las capacidades con que las universidades cuentan para producir más y mejores mercancías, ello según lo que les corresponde hacer de acuerdo al espacio geoeconómico donde están ubicadas. En el caso de nuestra universidad, sobre todo, aunque no únicamente, para producir "profesionales útiles a la patria", "recursos humanos de la mejor calidad", susceptibles de ser valorados como un "capital humano" óptimo y privilegiándose 
para eso aquellas disciplinas que lo consiguen. Por ejemplo, nuestra antigua Facultad de Economía se transforma en Facultad de Economía y Negocios para formar no solo economistas, sino también buenos agentes comerciales, y nuestra antigua Facultad de Ciencias Políticas se transforma en Instituto de Asuntos Públicos para formar no solo politólogos, sino buenos administradores para la burocracia estatal y privada, en tanto que otras facultades reorientan sus labores de investigación con vistas a convertirse, tanto ellas como quienes se forman en ellas, en proveedores de servicios. Todo eso mientras que se erradican o se mantienen con la rienda corta aquellas disciplinas que no generan dicho capital o que no lo generan óptimamente, reduciéndose esas otras, que son las humanísticas, a la enseñanza de destrezas decorativas o competencias serviciales: a redactar correctamente, a hablar y escribir más idiomas que el propio, a adquirir cierto barniz literario y artístico, a conocer las efemérides en la historia del país y del mundo...

Para un mejor cumplimiento de estos propósitos, se han puesto en ejercicio una serie de aparatos de diseño y control. Desde hace 20 años, un aparato de diseño poderoso, engendrador del modelo universitario ideal para la época en que vivimos (no el único, aunque hay que reconocer que, al margen de sus rasgos singulares, todos parten de las mismas premisas), es el de los acuerdos de Boloña de 1999. Concurrieron en esos acuerdos las universidades europeas de 30 naciones, que incluye a los países del Espacio Europeo de Libre Comercio y a los países del este y centro del continente, con la intención, primero, de unificar sus respectivos formatos (las prioridades de contenido y la organización de los curricula, la homogenización de los mismos, la adopción del sistema de créditos para facilitar el manejo de las equivalencias, la movilidad de profesores y estudiantes, el número de estudiantes por programa y el número de deserciones y las titulaciones, los tiempos y las exigencias de titulación, entre otros) y, en segundo lugar y dicho esto expresamente, en adecuar el formato resultante a las necesidades del orden global ${ }^{9}$. Licenciar, magisterear y doctorar inyectando en los candidatos a tales grados académicos los contenidos necesarios para sus actividades futuras en ese ámbito y no en otro y ello en el menor tiempo posible (la tan de moda "internacionalización" de la vida académica obedece al mismo impulso).

Para convertir el diseño en realidad, surgen los aparatos de control: los internos, los nacionales y los globales. Control que la universidad misma ejerce sobre los suyos, el que el estado nacional establece sobre esa misma gente y el que ciertas organizaciones supranacionales también utilizan. En estos controles convergen los propósitos instrumentales con los de la (vieja) aspiración de "cientificizar" las

9 En el primer punto de la "Declaración de Boloña" se lee el llamado a una homogenización de títulos que favorezca "la employability (ocupabilidad) de los ciudadanos europeos y la competitividad internacional del sistema europeo de enseñanza superior”. En línea. En una declaración subsiguiente, de 2007, esta vez en Londres, se reitera que el "EEES [Espacio Europeo de Educación Superior] es un escenario global". 
humanidades conforme al paradigma de las ciencias físicomatemáticas y biológicas $^{10} \mathrm{y}$ asegurando así que las cosas se estén haciendo como deben hacerse, que las acciones que se ejecutan tengan como meta el objetivo presupuestado. Para no demorarme en otras copias: que los licenciados concluyan su formación en un máximo de tres años y sin tesis, que los magísteres hagan lo propio solo en dos y con una tesina o a lo mejor sin ninguna y que los doctores se doctoren en cuatro con una tesis de espectro limitado y con un número de páginas ídem. Una tesis "de Estado", como la legendaria de Marcel Bataillon sobre Erasmo y España, de 1921, hoy sería improbable en el centro del mundo y en la periferia inconcebible. Ahora bien, si los programas humanísticos observan estas y las demás normas de moderación de sus pretensiones, serán premiados. Si no las observan, van a verse en la dura circunstancia de afrontar el castigo.

El premio consiste principalmente en una "acreditación" del programa del caso por parte de unos organismos a los cuales se habrá premunido (¿quiénes los habrán premunido?) con el poder necesario para otorgarla. La acreditación a que me refiero es obscenamente homóloga al sello de calidad que lucen algunos de los abarrotes que se expenden en el supermercado. Nacieron tales dispositivos en Estados Unidos, al parecer en los años '60, debido a que la heterogeneidad universitaria de ese país los hacía imprescindibles, imitándose después en los otros, entre ellos en el nuestro. Sus decisiones pueden ser menos o más generosas (acreditación con una duración de más y menos años, por lo pronto), y abrir o no abrir las compuertas a nuevos beneficios (becas para los estudiantes, por ejemplo).

El castigo consiste en la no acreditación, en primer lugar, un desenlace funesto ni qué decirse tiene. $\mathrm{O}$, en una decisión que también será mala, pero un poco menos mala, cuando se acorta el tiempo de la acreditación con la mengua consiguiente de las oportunidades que se le asocian.

Por supuesto, una buena acreditación redunda en el incremento del "prestigio" de la unidad académica que se habrá sometido al proceso evaluador, así como en el de la institución a la que ella pertenece, la que paralelamente se estará evaluando en su totalidad. Los resultados se dan a conocer de manera oficial. Más y mejores estudiantes se matriculan donde y cuando es posible exhibir buenos números. Las universidades privadas, que venden la educación que imparten y que están siempre en

10 "El método empírico exige que la cuestión del valor de los diversos procedimientos de que el pensamiento se sirve para resolver sus tareas se decida histórico-críticamente dentro del cuerpo de esas mismas ciencias, y que se esclarezca mediante la consideración de ese gran proceso cuyo sujeto es la humanidad misma la naturaleza del saber y del conocer en este dominio. Semejante método se haya en oposición con otro que recientemente se practica con excesiva frecuencia por los llamados positivistas, y que consiste en deducir el concepto de ciencia de la determinación conceptual del saber obtenida en el trabajo de las ciencias de la naturaleza, resolviendo luego con ese patón qué actividades intelectuales merecerán el nombre y el rango de ciencia". Dilthey. Introducción..., 13. 
busca de clientela fresca, desarrollan a partir de tales datos, vastas (y bastas) campañas de publicidad. Como si eso no bastara, si la institución ha sido bien "rankeada" por las agencias internacionales, Shanghai, QS, Times Higher Education, que (dicho sea de paso) son análogas a las que rankean el "riesgo país" de las economías nacionales, J.P. Morgan Chase o Standard \& Poor's, miel sobre hojuelas.

Con vistas a lograr éxito en el proceso de acreditación, el programa (el de un área específica, el de una facultad o el de la universidad en su conjunto) tendrá que elaborar un "plan" de desempeño que sea persuasivo y que de ese modo ponga a la unidad correspondiente a salvo de "performances" académicas vergonzosas. Procurará parecerse ese plan a los de las "ciencias duras" y para eso distinguirá con severidad y precisión "fortalezas" y "debilidades", lo que determina que los profesores e investigadores van a verse en la obligación de dar una cuenta detallada de cuánto, cómo y dónde están haciendo lo que hacen, en cada momento de su desempeño académico (prácticas "de comisaría", la llamó el maestro Félix Schwartzmann en un exabrupto feliz que le escuché hace no tanto tiempo). Primero haciéndolo ante las autoridades universitarias, las que tienen inmediatamente por sobre sus cabezas y que son por eso sus controladores preliminares, y luego ante las extrauniversitarias, para lograr al cabo la tan deseada acreditación, y también cuando postulan a algún financiamiento proveniente desde afuera, por ejemplo, el estatal de FONDECYT, ANID u otros. Número de papers por año, índole "científica" de los mismos, revistas indexadas en que se habrán publicado, docencia y servicios "relevantes".

He ahí la causa de los "criterios manageriales", de los que no sin alarma se percata el argentino Carlos Hoevel ${ }^{11}$. No sé yo cuánto es el tiempo que los profesores universitarios empleamos hoy respondiendo a los requerimientos que nos hacen los administradores, pero sospecho que es más del que empleamos en preparar nuestras clases o en nuestros trabajos de investigación. Simultáneamente, la estructura de la universidad se reconfigura. Es cada vez menos la "república de los sabios" con que soñaba Kant, y cada vez más una entidad en la que pululan los tecnócratas y los burócratas y en la que los proyectos que se emprenden requieren, por lo tanto, de una tramitación y un visto bueno que no es académico.

Pero no se trata únicamente de un exceso de tecnocracia y burocracia. Si ese fuera nuestro único problema, la situación sería menos grave de lo que es y por lo mismo más fácil de abordar. Porque, como Kant lo percibió bien, el corazón de la universidad moderna lo constituye el principio de autonomía y este es una derivación o, mejor dicho, una traducción y una extensión, hacia el ámbito universitario, de la autonomía que la burguesía francesa insurrecta consiguió a fines del siglo XVIII para

11 Carlos Hoevel. La industria académica. La universidad bajo el imperio de la tecnocracia global (Buenos Aires: Teseo, 2021), 20. 
el sujeto moderno. La autonomía del sujeto moderno pone el acento en el cambio desde la antigua condición de súbdito a la actual de sujeto o, en otra palabras, en la fortaleza y la libertad que este tiene o debiera tener para decidir respecto de las órdenes de cualquier poder heterónomo, libertad desde luego para pensar y poner de manifiesto lo pensado (artículo 11 de la Declaración de 1789).

Releída universitariamente, esa autonomía del sujeto moderno es la que se prolonga hasta la universidad moderna y hace que esta se reconozca a sí misma como tal, pues quienes la formamos habremos concluido que, para un rendimiento máximo de su identidad, la que consiste en ser un ente de educación superior que se ha puesto a la altura de las demandas que le plantea su tiempo, es preciso que la universidad cuente con dicho atributo, siendo este el sinónimo de una independencia que ha de ser máxima igualmente y cuyos parámetros ella, y nadie más que ella -la comunidad universitaria de los pares-, es capaz de fijar de una manera legítima y confiable. Por eso, llamarse, como se llama una de las universidades privadas chilenas, "universidad autónoma", es una redundancia ingenua, por no decir algo peor. Una universidad moderna o es autónoma o no es universidad.

La dependencia de la universidad contemporánea de los mecanismos de diseño y control no es en consecuencia un simple capricho burocrático, más o menos molesto, sino que pone en jaque, inevitablemente, su autonomía. En rigor, aunque haya académicos involucrados en los procesos evaluadores, no son ellos los que diseñan y controlan. Los académicos de marras, que trabajan para las oficinas de marras, tal como las autoridades universitarias a quienes me referí hace un rato, realizan un trabajo cuyos fondos y formas han sido predeterminados. Son tuercas de una máquina que funciona y que va a seguir funcionando de la misma manera con prescindencia de qué y cuánto sus operadores hagan para darle una apariencia alternativa. Posee una lógica propia y es esa lógica la que permea cada una de sus partes, cuáles o quiénes quiera que estos sean.

Me interesa insistir ahora en la puesta en jaque de la autonomía universitaria.

Así como la libertad es un atributo constitutivo del sujeto moderno, también la libertad es un atributo constitutivo de la universidad moderna. Más precisamente: en ambos casos, la libertad constituye un principio identitario y, por ende, no negociable. De lo contrario, uno y otra se arriesgan a un menoscabo en el ser. El sujeto moderno no es el que es si carece de libertad. Tampoco la universidad moderna es lo que es, o puede ser descrita según aquello que pretende ser, sino cuenta con toda la independencia que requiere para decidir acerca de sí misma y acerca de su funcionamiento. Puede ser un ente que instruye a las personas para el ejercicio de determinadas competencias profesionales (la diferencia entre educación e instrucción no es insignificante en este sentido), puede también suministrar 
temas entretenidos de conversación e incluso puede fomentar un cierto tipo de investigaciones (las que no cuestionan al sistema y cooperan en cambio con su buena marcha, por lo que no alteran su inclinación instrumental. La diferencia entre creación e innovación es al respecto decisiva), pero nada de eso hace de ella una universidad moderna. Una universidad moderna es más que eso. Para mí es el ente donde la cultura del pueblo moderno se formaliza y desde donde ella se le devuelve a ese mismo pueblo como una posibilidad de conducta. Esto es lo que hoy está en peligro y no solo en nuestro país.

¿Qué hacer entonces?

Entender, en primer lugar, que desde el punto de vista filosófico las partes no reproducen al todo necesariamente, que es posible que la parte esté, por coerción o por voluntad propia, dentro del todo, replicándolo, pero que no es menos posible que deje de estarlo o que lo haga bajo ciertas condiciones. Aunque puede ocurrir, y en la periferia del mundo es lo que suele emprenderse y con resultados a menudo bochornosos ("Éramos una máscara, con los calzones de Inglaterra, el chaleco parisiense, el chaquetón de Norteamérica y la montera de España”, es lo que escribió Martí en "Nuestra América"12), la replica mecánica no es un destino insoslayable.

En cambio, las partes pueden hacer pesar su autonomía, lo que quiere decir que ellas pueden hacer pesar lo que son, pues poseen una sustancialidad que es suya y solo suya, la que debiera identificarse, relevarse, defenderse y preservarse, ya que esa sustancialidad constituye un plus eficaz que evidencia lo que a cada una le es privativo, pero sin que ello suponga la cancelación de un encuentro horizontal con las fuerzas hegemónicas. Que las partes del todo sean celosas de sus diferencias, que las conozcan y las hagan valer, ese es un punto de partida y está bien. Pero asimismo está bien que ello no sea algo que les impida tratar con el todo. La verdadera cuestión es cómo hacer para que el encuentro sea horizontal y fructífero.

Esto significa que yo creo que existen culturas diferenciadas entre el centro hegemónico y la periferia hegemonizada y, más precisamente aún, entre lo que vemos, somos, hacemos y decimos en América Latina y lo que ven, son, hacen y dicen quienes habitan en los países del centro del mundo. Pero junto con eso creo también que tales diferencias necesitan ser ponderadas, en primer lugar y que, en segundo lugar, aunque la parte más fuerte trate de meternos en (su) cintura, podemos resistirla y resignificarla.

12 José Martí, "Nuestra América” en Obras completas Vol. VI (La Habana: Editorial Nacional de Cuba, 1963), 20. 
Discrepo en consecuencia de quienes opinan que la cultura de la metrópoli ha de trasladarse a la periferia impoluta, tanto como discrepo de los autoctonistas, de los que rechazan cualquier vínculo que pudiera entablarse entre la una y la otra (cuando en verdad se ha entablado ya, partícipes como hemos sido de una cohabitación que en América Latina dura 500 años). Pienso, en definitiva, que la diferencia es real, pero no inmanejable. Términos tales como "transculturación" (Rama 1982), "deglución" (de Andrade 2001) o "apropiación" (Subercaseaux 1988) procuran generar un piso para conceptualizar esas relaciones interculturales asimétricas.

Todo esto sugiere la necesidad de que le hagamos un lugar en nuestra propuesta al factor poder. Constataremos entonces que la actitud mimética no es, o no es casi nunca, una elección. Que habitualmente es una imposición, es decir una obligación que directa o indirectamente descargan sobre nosotros las fuerzas que dominan en el todo, en el presente caso las fuerzas del orden capitalista mundial y sus managers en medio de una coyuntura de crisis y cuando, para hacer frente a esa crisis, ellos recurren, entre otras medicinas, a la globalización. Si estamos en efecto asistiendo al coletazo más fuerte de un sistema enfermo y furioso, nosotros debemos actuar teniendo en cuenta ese desafío, habiendo tomado nota de que el lobo anda suelto, que tiene hambre y que al dejarlo entrar en nuestra casa arriesgamos convertirnos en su almuerzo. Esto no es algo que sea discutible, pero tampoco son datos que tengan que paralizarnos, sino obligarnos a un empleo afinado de la inteligencia.

Lo mejor para eso es volver sobre lo que somos, verlo y valorarlo nosotros mismos, y hacérselo ver y valorar a nuestros conciudadanos de una manera clara y distinta. Volver sobre la definición de las humanidades como la cultura que subyace a los derechos (y, ojalá, a las actuaciones) del pueblo moderno y a las disciplinas universitarias que las acogen y diseminan como el locus de su formalización, y sin perder de vista el que la cultura de la cual estamos hablando no es ni uniforme ni estática, sino que se peculiariza y se reformula, esto último a lo largo de la existencia histórica de aquellos entre quienes se aloja y en tanto cuanto estos lo consideran apropiado.

Importan por consiguiente las diferencias y sus reformulaciones periódicas, pero no importa menos el que nos convenzamos de la necesidad profunda de un cultivo serio de las humanidades bajo cualquier circunstancia. Esto porque los seres humanos no tenemos acceso a la realidad en cuanto tal, ya que la realidad nos es incognoscible en sí misma, que la única manera en que podemos establecer contacto con ella, conocerla, cuidarla, preservarla o cambiarla, es asumiéndola como un objeto cultural. $\mathrm{O}$, dicho más al hueso, las humanidades, que son la cultura del pueblo moderno, son también el único medio con que el pueblo moderno cuenta 
para, a partir de lo que ellas le proponen, dotar al mundo circundante de sentido y actuar en él de una manera racional. Si esto es así, y yo creo que lo es, entonces Kant estaba en lo cierto y las humanidades preceden a cualquier otro esfuerzo de conocimiento, e incluyendo entre ellos el de las ciencias y las tecnologías. Constituyen el momento de la razón, el previo a la instrumentalidad, y que reaparece después, cuando la instrumentalidad ya ha hecho su parte, en la primera oportunidad permitiéndonos "imaginar" y "pensar" y en la segunda contribuyendo a las tareas de la "emancipación".

¿Tengo que decir que declarar caduca la cultura de la modernidad, que es la que le proporciona su base a las humanidades y así nos permite saber quiénes somos y en qué mundo vivimos, es un ejercicio de frivolidad irresponsable?

Por último, en el ámbito universitario y ateniéndonos al entendimiento inteligente de las partes con el todo, yo considero que necesitamos determinar la relación de las disciplinas humanísticas con la institución en que se insertan y con las disciplinas aledañas. Al respecto, subrayo: a) la conveniencia de invitar al residuo premoderno, esotérico y prejuicioso, a que levante su campamento en un espacio que no sea el de los planteles de la educación superior; b) la inconveniencia de que nos hagamos eco en la universidad la definición de las humanidades como un mero "ornamento", que es correlativa a una definición de las artes en el mismo y mal sentido; c) derivada de lo anterior, la inconveniencia de consentir y aplaudir su banalización mediática, así como cualquiera otra que las reduzca a los fines del entretenimiento masivo, lo que no quiere decir que tengamos que renunciar a un empalme mutuamente fructuoso de las humanidades con la revolución digital; d) la inconveniencia absoluta de acatar su reducción pedagógica a un simple adiestramiento del alumno en "habilidades"; e) la conveniencia de que los universitarios nos conozcamos y sepamos en qué consiste nuestra misión de cultura, en el significado más fuerte de este término, que no es otro que el de las humanidades, y que seamos por eso capaces de enfrentarnos con el modelo global y de sortear de ese modo las deformaciones a las que este nos expone; y f) aun reconociendo que la división del trabajo intelectual reditúa en una mayor productividad del mismo y que por ende no es descartable, insisto en que constituye una mala política asumir posiciones que radicalicen las diferencias, exacerbando parroquialmente el contenido específico de las disciplinas. Por el contrario, lo que tiene que estimularse a mi juicio son las coincidencias y la colaboración, las de las humanidades con la educación y las ciencias sociales, en primerísimo lugar.

¿Cómo?

Mediante un trabajo trans e interdisciplinario, que por lo demás es la forma con que todas las disciplinas del conocimiento se enriquecen en tiempos normales y 
se recargan en tiempos difíciles. Esto significa que las acusaciones que los "especialistas" nos hacen a quienes favorecemos una perspectiva de trabajo de ese tipo no sólo son injustas, sino equivocadas. Esos buenos colegas nuestros no se percatan de que la introducción de una perspectiva que cruce las disciplinas, que es indispensable en las circunstancias de crisis, constituye también un beneficio en las circunstancias de paz.

\section{Bibliografía}

Andrade, Oswald de. Escritos antropófagos. Trs. y Eds. Alejandra Laera y Gonzalo Moisés Aguilar. Buenos Aires: Corregidor, 2001.

Bello, Andrés. "Discurso pronunciado en la instalación de la Universidad de Chile el día 17 de septiembre de 1843" en Obras completas de Don Andrés Bello. Vol. VIII. Opúsculos literarios y críticos III. Santiago de Chile: Pedro G. Ramírez, 1885, pp. 303-313.

Benjamin, Walter. "La obra de arte en la época de la reproductibilidad técnica. Tr. Andrés E. Weikert. México: Itaca, 2003.

Chihuailaf Nahuelpan, Elicura. Recado confidencial a los chilenos. Santiago de Chile: LOM, 1999.

Dilthey, Wilhelm. Obras de Wilhelm Dilthey. Introducción a las ciencias del espiritu. En la que se trata de fundamentar el estudio de la sociedad y de la historia. Tr. Eugenio Imaz. México y Buenos Aires: Fondo de Cultura Económica, 1949.

Gubern, Román. Metamorfosis de la lectura. Barcelona. Anagrama, 2010.

Heidegger, Martin. "La pregunta por la Técnica" en Filosofia, ciencia y técnica. $4^{\mathrm{a}}$ ed. Francisco Soler, Tr. y Jorge Acevedo, Ed. Santiago de Chile: Universitaria, 2003.

Hobsbawm, Eric. Historia del siglo XX 1914-1991. Trs. Juan Faci, Jordi Arnaud y Carme Castells. Barcelona. Crítica, 2019.

Hoevel, Carlos. La industria académica. La universidad bajo el imperio de la tecnocracia global. Buenos Aires: Teseo, 2021.

Horkheimer, Max y Theodor W. Adorno. Dialéctica de la Ilustración. Fragmentos filosóficos. Tr. Juan José Sánchez. $9^{a}$ ed. Madrid: Trotta, 2009.

Kant, Immanuel. El conflicto de las facultades. Tr. Roberto R. Aramayo. Madrid: Alianza, 2003.

Martí, José. "Nuestra América" en Obras completas. Vol. VI. La Habana: Editorial Nacional de Cuba, 1963. 
Marx, Carlos. El Capital. Crítica de la economía política. Tr. Wenceslao Roces. Vol. I. México: Fondo de Cultura Económica, 1978.

Rama, Ángel. Transculturación narrativa en América Latina. México: Siglo XXI, 1982.

Rojo, Grínor. "Capitalismo, humanidades y pandemia" en Proposiciones. Ensayos de teoría crítica. Santiago de Chile: Universitaria, 2021. En prensa.

Subercaseaux, Bernardo. "La apropiación cultural en el pensamiento y la cultura de América Latina". Estudios Públicos, 30 (1988), 125-135.

Varios autores. Declaración de Bolonia: http://ees.umh.es/contenidos/Documentos/DeclaracionBolonia.pdf (consultada, 30, VIII, 2021)

Zizek, Slavoj. La vigencia de El manifiesto comunista, tr. Samiá Alou. Anagrama. Barcelona, 2018. 